\title{
Pengaruh Model Pembelajaran Kooperatif Tipe Course Review Horay (CRH) Terhadap Hasil Belajar Matematika Siswa pada Materi Persamaan Linear Satu Variabel di Kelas VII SMP Negeri Rantau Selatan
}

\section{The Effect of Cooperative Learning Model Course Review Horay (CRH) Type on Student Mathematics Learning Outcomes in One Variable Linear Equation Material in Class VII Middle School of South Rantau}

\author{
Lily Rohanita Hasibuan \\ Program Studi Pendidikan Matematika, STKIP Labuhan Batu \\ Jalan Sisingamangaraja No. 126A, KM, 3,5 Aek Tapa Rantauprapat email: Irohanita30@gmail.com
}

\begin{abstract}
Abstrak
Tujuan penelitian ini yaitu untuk mengetahui pengaruh model pembelajaran kooperatif tipe Course Review Horay $(\mathrm{CRH})$ terhadap hasil belajar matematika siswa pada materi persamaan linear satu variabel di kelas VII SMP Negeri Rantau Selatan. Sampel yang digunakan dalam penelitian ini 38 siswa. Metode penelitian yang digunakan adalah quasi eksperimen, teknik pengumpulan data yaitu observasi dan tes. Analisis data dengan menggunakan teknik analisis statistic deskriptif dan statistic inferensial yaitu uji-t. Berdasarkan analisis data pada kelas eksperimen diperoleh rata-rata nilai pretes 34,47 dan postes 75,92 dengan rata-rata peningkatan sebesar $63,25 \%$ atau Gain 0,63 kategori sedang dengan standar deviasi 0,1365 . Untuk kelas control diperoleh nilai rata-rata pretes 35,13 dan postes 68,68 dengan rata-rata peningkatan hasil belajar kelas kontrol sebesar 50,88 \% atau Gain 0,51 kategori sedang dengan standar deviasi 0,1721 . Dari hasil uji beda nilai kedua kelas pada taraf signifikan $\alpha=0,05$ diperoleh thitung $=3,475$ dan tabel $=1,668$ dengan membandingkan antara thitung dan tabel diperoleh thitung $>$ trabel atau 3,475>1,668 maka $\mathrm{H}_{a}$ diterima artinya peningkatan hasil belajar matematika siswa yang diajarkan dengan model pembelajaran Course Review Horay $(C R H)$ lebih tinggi daripada model pembelajaran konvensional. Dengan demikian dapat disimpulkan bahwa model pembelajaran kooperatif tipe Course Review Horay $(\mathrm{CRH})$ member pengaruh yang lebih baik terhadap hasil belajar matematika siswa daripada model pembelajaran konvensional pada materi persamaan linear satu variabel di kelas VII SMP Negeri Rantau Selatan.
\end{abstract}

Kata kunci : Model pembelajaran Course Review Horay (CRH), Hasil Belajar

\begin{abstract}
The purpose of this study is to determine the effect of cooperative learning model Course Review Horay (CRH) type on students' mathematics learning outcomes in one variable linear equation material in class VII South Overseas Middle School. The sample used in this study was 38 students. The research method used was quasi-experimental, data collection techniques namely observation and tests. Data analysis using descriptive statistical analysis techniques and inferential statistics, namely t-test. Based on data analysis in the experimental class, the average score of pretest was 34.47 and posttest was 75.92 with an average increase of $63.25 \%$ or gain of 0.63 in the medium category with a standard deviation of 0.1365 . For the control class, the average score of pretest was 35.13 and posttest 68.68 with an average increase in learning outcomes in the control class of $50.88 \%$ or Gain of 0.51 in the medium category with a standard deviation of 0.1721 . From the results of different test values of the two classes at a significant level $\alpha=0.05$, obtained $t_{\text {count }}=3.475$ and table $=1.668$ by comparing between tcount and t table obtained tcount> ttable or $3.475>1.668$ then $\mathrm{Ha}$ accepted means increasing student mathematics learning outcomes taught with models Course Review Horay $(\mathrm{CRH})$ learning is higher than conventional learning models. Thus it can be concluded that the cooperative learning model type Course Review Horay (CRH) gives a better influence on students' mathematics learning outcomes than the conventional learning model in one variable linear equation material in class VII Middle School of South Rantau.
\end{abstract}

Key Words : Learning model Course Review Horay $(\mathrm{CRH})$, Learning Outcomes 


\section{Pendahuluan}

Matematika merupakan bagian dari pendidikan. Belajar matematika merupakan salah satu sarana berfikirr ilmiah dan logis serta mempunyai peran penting dalam upaya meningkatkan kualitas sumber daya manusia. Tak heran jika matematika menjadi mata pelajaran wajib bagi siswa SD hingga SLTA dan bahkan juga perguruan tinggi. Ada banyak alasan tentang perlunya belajar matematika. Abdurrahman \& Mulyono (2003)[1]. mengemukakan 5 alasan perlunya belajar matematika karena matematika merupakan (1) Sarana berfikir yang jelas dan logis, (2) sarana untuk memecahkan masalah kehidupan sehari-hari, (3) sarana mengenal pola-pola hubungan dan generalisasi pengalaman, (4) sarana untuk mengembangkan kreativitas, dan (5) sarana untuk meningkatkan kesadaran terhadap perkembangan budaya.

Oleh sebab itu, mengingat pentingnya matematika dalam kehidupan maka guru bidang studi matematika dituntut untuk kreatif menciptakan, merencanakan, pembelajaran matematika dengan sebaikbaiknya.

Berdasarkan hasil observasi yang telah dilakukan di SMP Negeri Bilah Hulu menunjukkan rendahnya keaktifan siswa pada saat pembelajaran. Hal ini terlihat dari sebagai besar siswa kurang aktif seperti mengajukan pertanyaan, menjawab pertanyaan yang dilontarkan guru ataupun merespon dan menanggapi jawaban dari temannya. Dalam pembelajaran, guru menerapkan model pembelajaran yang berpusat pada guru dimana guru cenderung mentransfer pengetahuan yang dimiliki secara langsung kepada siswa. Kegiatan pembelajaran matematika yang dilaksanakan hanya memposisikan siswa sebagai pendengar ceramah guru, siswa diajarkan teori, diberikan contoh, serta diberikan latihan soal. Siswa tidak didorong untuk aktif dalam mengkonstruksi pengetahuannya sendiri.

Berdasarkan hasil wawancara dengan salah satu guru bidang studi amtematika mengatakan, kegiatan belajar dan mengajar selama ini masih berpusat pada guru, model pembelajaran yang sering digunakan adalah model pembelajaran langsung karena sudah terbiasa serta lebih mudah dalam melaksanakannya dikelas.nilai siswa untuk mata pelajaran matematika tergolong rendah hal ini dilihat dari nilai rata-rata siswa pada semester ganjil yaitu 69,85 sednagkan nilai KKM sekolah tersebut adalah 75. Minat belajar matematika siswa juga rendah, banyak siswa yang tidak menyukai pelajaran matematika karena merupakan pelajaran yang sulit.

Berdasarkan permasalahan tersebut dalam mengajar matematika model pembelajaran yang masih bersifat teacher centered perlu diganti dengan model pembelajaran yang bersifat student centered. Hal ini bertujuan agar siswa dapat berperan aktif selama proses belajar berlangsung. Pentingnya keaktifan siswa dalam pembelajaran matematika sebagaimana yang dikemukan oleh Winataputra, S. (2008)[2] Pengajaran matematika tidak sekedar berupaya menyampaikan berbagai aturan, defenisi, dan prosedur agar dihapalkan para siswa, tetapi untuk melibatkan pada siswa sebagai partisipan yang aktif dalam proses belajar karena partisipasi aktif para siswa berpotensi untuk memperluas pemahaman konsep matematis mereka.

Oleh karena itu, diperlukan suatu model pembelajaran yang dapat menciptakan suasana belajar yang menyenagkan sehingga dapat menumbuhkan minat dan keaktifan siswa dalam belajar yaitu model pembelajaran kooperatif tipe Course Review Horay $(\mathrm{CRH})$.

Sama halnya dengan model pembelajaran kooperatif pada umumnya, dimana siswa dikelompokkan dalam kelompok kecil yang heterogen dengan kemampuan akademik yang berbeda tujuannya agar mereka saling belajar, bekerja sama menjadi tutor bagi teman sebayanya dan memastikan bahwa seluruh anggota tim telah menguasai pelajaran tesebut. Pada tahap evaluasi seluruh siswa dalam kelompok diberi tes tentang materi itu, pada saat tes ini mereka tidak diperbolehkan saling membantu. Bedanya dengan model pembelajaran kooperatif tipe lain, pada model pembelajaran kooperatif tipe Course Review Horay $(\mathrm{CRH})$ siswa yang menjawab benar harus menyanyikan Yel - yel kelompok mereka. Kemudian, banyaknya yel-yel yang diperoleh anggota yang berasal dari kelompok itu diakumulasikan untuk menjadi nilai kelompok dan kelompok yang memiliki skor tertinggi atau jumlah yelyel yang paling banyak diberi hadiah atau penghargaan oleh guru. Jadi, ciri khas pada model pembelajaran kooperatif tipe Course Review Horay (CRH) ini terletak pada penggunaan yel-yel dalam pembelajaran. Yel-yel yang dinyanyikan dapat menjadi hiburan tersendiri bagi setiap orang yang berada di kelas sehingga suasana belajar menjadi lebih menyenangkan.

Perlunya model pembelajaran yang dapat menciptakan suasana belajar yang menyenangkan adalah dapat membuat proses berpikir siswa menjadi lebih optimal sehingga lebih mudah untuk mengembangkan seluruh potensi siswa karena siswa terbebas dari rasa takut dan menegangkan Sanjaya (2014)[3].

Sejalan dengan hal itu, maka dengan menerapkan model pembelajaran kooperatif tipe Course Review Horay $(\mathrm{CRH})$ dalam pembelajaran matematika diharapkan dapat memupuk minat belajar matematika siswa dan mendorong siswa untuk aktif dalam mempelajari matematika, sehingga pada akhirnya dapat berpengaruh baik terhadap hasil belajar matematika siswa. 


\section{Metode Penelitian}

Penelitian ini termasuk penelitian kuantitatif dengan menggunakan metode quasi eksperimen. Dalam penelitian ini menggunakan perlakuan pembelajaran matematika dengan menggunakan model pembelajaran tipe Course Review Horay $(\mathrm{CRH})$ yang selanjutnya disebut kelas eksperimen. Kelas ini akan memperoleh pretest dan posttest. Penelitian ini dilaksanakan di SMP Negeri 2 Bilah Hulu Kabupaten Labuhanbatu. Populasi dalam penelitian ini adalah seluruh siswa kelas VII SMP Negeri 2 Bilah Hulu. Sampel dalam penelitian diambil dari populasi terjangkau. Berdasarkan karakteristik yang telah dijelaskan maka pemilihan sampel dilakukan dengan Purposive Sampling (Sampling Pertimbangan) merupakan metode penetapan responden untuk dijadikan sampel berdasarkan pada kriteria-kriteria tertentu. Dengan mengambil satu kelas dari 2 kelas yaitu kelas VII-6 dan VII-5 menggunakan sebanyak 38 siswa. Instrument yang digunakan dalam penelitian ini berupa tes dan Imbar obseravsi, yaitu tes berbentuk pilihan berganda yang sebanyak 30 butir soal masingmasing memiliki 4 option dalam jawaban untuk mengukur hasil belajar siswa yang diberi perlakuan berupa model pembelajaran Course Review Horay $(\mathrm{CRH})$ maupun yang tidak diberi perlakuan yaitu model pembelajaran konvensional dan observasi digunakan untuk aktivitas siswa pada kelas eksperimen berlangsung yang diberi perlakuan model pembelajaran kooperatif tipe Course Review Horay $(\mathrm{CRH})$ dan menerapkan model pembelajaran secara lamgsung (konvensional). Penelitian ini menggunakan analisis kuantitatif yaitu suatu teknik analisis yang penganalisaannya dilakukan dengan perhitungan, karena berhubungan dengan angka, yaitu dari hasil tes kemampuan hasil belajar matematika yang diberikan.

\section{Hasil Penelitian dan Pembahasan}

\section{Hasil Penelitian}

Deskripsi Data Hasil Kelas Eksperimen

Untuk mengetahui gambaran deskripsi data pretest hasil belajar matematika siswa sebagaimana berdistribusi pada tabel dibawah ini:

Tabel 1. Hasil Pretest Kelas Eksperimen Kemampuan Pemahaman Konsep

\begin{tabular}{|c|c|c|}
\hline \multirow{2}{*}{ No } & Pemusatan dan Penyebaran Data & Pretest \\
\cline { 3 - 3 } & Mean & Eksperimen \\
\hline 1 & Standart Deviasi & 34.47 \\
\hline 2 & Varians & 0.1365 \\
\hline 3 & Skor Tertingi & 0.51 \\
\hline 4 & Skor Terendah & 40.00 \\
\hline 5 & & 20.00 \\
\hline
\end{tabular}

Berdasarkan hasil tes yang diberikan kepada siswa di kelas eksperimen dengan menggunakan model pembeljaran tipe Course Review Horay $(\mathrm{CRH})$ dengan jumlah siswa sebanyak 38, maka diperoleh deskripsi data hasil posttest sebagai berikut :

Tabel 2. Hasil Post-Tes Kelas Eksperimen Kemampuan Pemahaman Konsep

\begin{tabular}{|c|c|}
\hline Interval dan Penyebaran Data & Jumlah atau Nilai \\
\hline Mean & 75.92 \\
\hline Standar Deviasi & 0.1365 \\
\hline Varians & 0.51 \\
\hline Skor Tertingi & 90.00 \\
\hline Skor Terendah & 65.00 \\
\hline
\end{tabular}

Uji Normalitas Tes Hasil Belajar Matematika Siswa di Kelas Eksperimen

Berdasarkan data yang diperoleh dari nilai pretest dan posttest, maka diperoleh hasil uji normalitas seperti tabel dibawah ini: 
Tabel 3. Rekapitulasi Hasil Perhitungan Uji Normalitas di Kelas Eksperimen

\begin{tabular}{|l|l|c|c|c|}
\hline \multicolumn{1}{|c|}{ Data } & Kelas & $X_{\text {hitung }}$ & $X_{\text {tabel }}$ & Kesimpulan \\
\hline Pretest & VII-6 & 0.1077 & 0.1437 & Ho diterima (normal) \\
\hline Posttest & VII-6 & 0.1008 & 0.1437 & Ho diterima (normal) \\
\hline
\end{tabular}

Berdasarkan tabel 3 diatas menunjukkan bahwa data nilai pretest dan posttest hasil belajar matematika dengan menggunakan model pembelajaran Course Review Horay (CRH) di kelas eksperimen berdistribusi normal. Hal ini ditunjukkan dari nilai thitung yaitu 0.1077 dan 0.1437 lebih kecil dari nilai tabel yaitu 0.1077 dengan $\alpha=0,05$ dan $\mathrm{dk}=37$. Artinya $\mathrm{X}^{2}{ }_{\text {hitung }} \leq \mathrm{X}^{2}$ tabel, maka $\mathrm{H}_{\mathrm{o}}$ diterima

\section{Uji Homogenitas Tes Hasil Belajar Matematika Siswa di Kelas Eksperimen}

Setelah data pretest dan posttest berdistribusi normal, langkah selanjutnya data memiliki varians yang sama atau tidak. Hasil data dapat dilihat seperti tabel dibawah ini:

Table 4. Rekapitulasi Hasil Perhitungan Uji Homogenitas

\begin{tabular}{|l|c|c|c|c|c|}
\hline Data & Kelas & $\mathrm{N}$ & Fhitung & Ftabel & Kesimpulan \\
\hline Pretest dan Possttest & VII-6 & 38 & 1.591 & 1.73 & Homogen \\
\hline
\end{tabular}

Berdasarkan tabel 4 diatas diketahui bahwa nilai $F_{\text {hitung }}$ sebesar 1.591 dan $F_{\text {tabel }}$ sebesar 1.73 dengan taraf signifikan 0,05 dan $\mathrm{df}=38$, maka dapat disimpulkan 1,591<1,73 bahwa $\mathrm{H}_{\circ}$ diterima. Artinya bahwa data pre-test dan post-test kelas eksperimen bersifat homogen.

\section{Uji $\boldsymbol{t}$ Tes Kemampuan Hasil Belajar Matematika Siswa di Kelas Eksperimen.}

Setelah data berdistribusi normal dan homogen, maka dapat dilakukan uji t-test dengan teknik paired samples $t$-test. Hasil yang diperoleh dari perhitungan uji $t$ seperti tabel dibawah ini:

Tabel 5 Rekapitulasi Hasil Perhitungan Uji t di Kelas Eksperimen

\begin{tabular}{|c|c|c|c|c|}
\hline Data & Kelas & $\mathrm{N}$ & thitung & Kesimpulan \\
\hline Pretest dan postest & VII-6 & 38 & -0.295 & $\mathrm{H}_{0}$ ditolak $\mathrm{H}_{\mathrm{a}}$ diterima \\
\hline
\end{tabular}

Berdasarkan tabel 5 hasil perhitungan uji t yang ditunjukkan pada tabel diatas dengan taraf signifikan $\alpha=0,05 / 2=0,025$ (dua sisi). Kemudian dicari tabel pada tabel distribusi t dengan ketentuan $\mathrm{db}=\mathrm{n}-1, \mathrm{db}=38-1=37$. Sehingga $\mathrm{t}_{(0,0295)}=2,042$, sehingga dalam kasus ini tabel yang dimaksud adalah 1,68 dan $-0,295$. Jadi $2,042 \geq 1,68 \leq-0,295$ yang berarti terdapat pengaruh hasil belajar matematika yang menggunakan model pembelajaran Course Review Horay (CRH) di kelas eksperimen yang signifikan antara pre-test maupun post-test.

\section{Hasil Observasi Aktivitas Siswa}

Dalam menganalisis aktivitas siswa digunakan skala Likert. Jawaban setiap item instrumen yang menggunakan skala Likert mempunyai gradasi aktif dan cukup aktif. Observasi aktivitas berisi pernyataan-pernyataan yang berkaitan dengan aktivitas siswa terhadap pembelajaran matematika menggunakan model pembelajaran tipe Course Review Horay $(\mathrm{CRH})$. Hasil rekapitulasi aktivitas siswa dapat dilihat pada tabel berikut:

Tabel 6. Rekapitulasi Pertanyaan Positif Aktivitas Siswa

\begin{tabular}{|c|l|c|c|}
\hline Pertemuan & Jumlah Skor & Nilai & Keterangan \\
\hline I & 716 & 58,88 & Cukup Aktif \\
\hline II & 803 & 65,71 & Aktif \\
\hline III & 864 & 71,05 & Aktif \\
\hline Rata-rata & 151 & 83.88 & Aktif \\
\hline
\end{tabular}

Berdasarkan data diatas dapat disimpulkan bahwa persentase perkembangan aktivitas siswa dalam memperhatikan, mendengarkan penjelasan guru, megajukan pertanyaan, bekerja sama, 
memberikan jawaban dan menyampaikan ide-ide atau pendapat pada pertemuan pertama sampai pertemuan ketiga terus meningkat

\section{Pembahasan}

Berdasarkan pengujian hipotesis menggunakan uji t dengan teknik paired samples $t$-test untuk kelas eksperimen pada taraf signifikan $\alpha=0,05$ dengan $\mathrm{db}=\mathrm{n}-1$ yaitu $\mathrm{db}=38-1=37$ maka diperoleh nilai tabel sebesar $-1,995$ dan 1,995 (dua sisi), sedangkan nilai thitung diperoleh sebesar -0,295. Hal ini menunjukkan bahwa -ttabel $>$ thitung $<$ tabel yaitu $-1,995<-0,295<1,995$-maka Ho ditolak dan $\mathrm{Ha}$ diterima. Artinya bahwa kedua kelas antara kelas eksperimen dan control mempunyai kemampuan awal yang sama.

Setelah diketahui kemampuan awal siswa maka selanjutnya memberi perlakuan pada kedua kelas eksperimen diajarkan dengan model pembelajaran kooperatif tipe Course Review Horay (CRH) rata -rata hasil belajar siswa pada kelas ini adalah 75,29 dengan peningkatan rata-rata sebesar $63,25 \%$ atau Gain 0,63 kategori sedang. Sedangkan pada kelas control setelah diberi perlakuan rata -rata hasil belajar siswa menjadi 68,88 dengan peningkatan rata-rata sebesar 50,88\% atau Gain 0,51 kategori sedang. Maka Ha diterima artinya rata -rata peningkatan hasil belajar matematika siswa kelas eksperimen yaitu kelas yang diperlakuan model pembelajaran kooperatif tipe Course Review Horay (CRH) lebih tinggi dari nilai rata -rata peningkatan hasil belajar matematika siswa kelas control yaitu kelas yang diberi perlakuan model pembelajaran konvensional (model pembelajaran langsung).

Pengaruh model pembelajaran kooperatif tipe Course Review Horay $(\mathrm{CRH})$ terhadap aktif belajar siswa diperoleh bahwa dengan menggunakan model pembelajaran kooperatif tipe Course Review Horay $(\mathrm{CRH})$ aktivitas belajar siswa tergolong aktif. Siswa tidak hanya berperan sebagai penerima pelajaran melalui penjelasan guru secara verbal, tetapi siswa berperan aktif berfikir, bekerjasama, berdiskusi untuk menyelesaikan masalah yang ada dan mengembangkan sikap percaya diri siswa dalam proses pembelajaran. Berbeda halnya dengan model pembelajaran konvensional dengan posisi guru sebagai pengatur utama kegiatan siswa. Siswa hanya sebagai penerima informasi dari guru dan guru lebih banyak member penjelasan atau ceramah yang menjadikan siswa pasif, dengan kata lain proses pembelajaran hanya berlangsung satu arah.

Berdasarkan hasil penelitian dan pengujian hipotesis dapat disimpulkan bahwa model Course Review Horay $(\mathrm{CRH})$ member pengaruh yang lebih baik terhadap hasil belajar matematika siswa daripada model pembelajaran konvensional pada materi persamaan linear satu variabel di kelas VII SMP Negeri 2 Bilah Hulu Kabupaten Labuhan Batu.

\section{Kesimpulan}

Peningkatan hasil belajar siswa yang diberi perlakuan model pembelajaran kooperatif tipe Course Review Horay (CRH) dan Konvensional sama-sama member peningkatan terhadap hasil belajar siswa dengan kategori sedang. Dimana peningkatan hasil belajar siswa dari pretest ke posttes yang diberi perlakuan model pembelajaran kooperatif tipe Course Review Horay (CRH) rata-rata peningkatan sebesar $63,25 \%$ atau dengan nilai Gain 0,63 (sedang) dan yang diebri perlakuan model pembelajarankonvensional dengan rata-rata peningkatan 50,88\% atau dengan nilai Gain 0,51 (sedang). Berdasarkan hasil perhitungan uji t di dapat peningkatan hasil belajar matematika siswa yang diajarkan dengan model pembelajaran kooperatif tipe Course Review Horay (CRH) lebih tinggi daripada model pembelajaran konvensional. Berdasarkan hasil penelitian dan uji hipotesis bahwa model pembelajaran kooperatif tipe Course Review Horay $(\mathrm{CRH})$ member pengaruh yang lebih baik terhadap hasil belajar matematika siswa daripada model pembelajaran Konvensional (Model Pembelajaran Langsung) Pada Materi Persamaan Linear Satu Variabel di Kelas VII SMP Negeri 2 Bilah Hulu Kabupaten Labuhanbatu.

\section{Daftar Pustaka}

[1] Abdurrahman \& Mulyono. (2003). Pendidikan Bagi Anak Berkesulitan Belajar. Jakarta: Rineka Cipta

[2] Winataputra, S. (2008). Belajar dan Mengajar. Surakarta: Lima Aksara.

[3] Sanjaya, Wina. (2014). Strategi Pembelajaran, Jakarta: Kencana Prenada Media Group. 